\title{
SHORT-TERM ASSOCIATION BETWEEN AIR POLLUTION AND EMERGENCY ROOM ADMISSIONS FOR CHRONIC OBSTRUCTIVE PULMONARY DISEASE IN NIŠ, SERBIA
}

\author{
Suzana Milutinović, Dragana Nikić, Ljiljana Stošić, Aleksandra Stanković, Dragan Bogdanović
}

Public Health Institute Niš, Serbia

\begin{abstract}
SUMMARY
The present study assesses the short-term association between black smoke (BS) and sulphur dioxide $\left(\mathrm{SO}_{2}\right)$ levels in urban air and the daily number of emergency room admissions for chronic obstructive pulmonary disease (COPD) in Niš, Serbia.

Generalised linear models extending Poisson regression were fitted controlling for time trend, seasonal variations, days of the week, temperature, relative humidity, air pressure, precipitation, rainfall, snowfall, overcast, and wind velocity.

The emergency room admissions for all ages for COPD were significantly associated with previous-day level of BS and lag $0-2(1,60 \%$ and $2,26 \%$ increase per $10 \mu \mathrm{g} / \mathrm{m}^{3}$, respectively). After controlling for $\mathrm{SO}_{2}$, single lagged (lag 1 and lag 2) as well as mean lagged values of $\mathrm{BS}$ (up to lag 0-3) were significantly associated with COPD emergencies.

No effect was found for $\mathrm{SO}_{2}$, even after controlling for black smoke.

The present findings support the conclusion that current levels of ambient BS may have an effect on the respiratory health of susceptible persons.
\end{abstract}

Key words: air pollution, chronic obstructive pulmonary disease, emergency room admissions

Address for correspondence: S. Milutinović, Public Health Institute Niš, Zorana Đinđića 50, 18000 Nišs, Serbia. E-mail: suzana-m@bankerinter.net

\section{INTRODUCTION}

Studies conducted in very different environments have consistently observed that admissions due to chronic obstructive pulmonary disease (COPD) increased on days with high pollution levels (1-4). Recent results suggest that adverse health effects of air pollution exist at levels of pollutants around and below the current national and international air quality guidelines and standards (5).

People with COPD have been reported to be more susceptible to adverse health effects of air pollution than healthy people (6). There are good evidence that pollutants, either primarily generated by combustion sources or secondarily produced after chemical transformation in the atmosphere, aggravate pre-existing chronic respiratory conditions, such as COPD. Fine and ultrafine particles from combustion sources are the most likely causes of the respiratory effects $(7,8)$. Physical and chemical properties of particulate matter have been postulated to be determinants of toxicity: for example, metal content, oxidative potential, or being in the ultrafine size mode $(<0,10 \mu \mathrm{m})(9)$.

The short-term effects of pollutants have been the main focus for study, especially in time-series studies. Typically, effect estimates are given as an increase in the health outcome associated with a $10 \mu \mathrm{g} / \mathrm{m}^{3}$ increase in pollutants concentrations. Acute effects are well established for total non-accidental and respiratory mortality, as well as respiratory hospital and emergency room admissions (10).

This is the first study providing quantitative estimates of the short-term effects of air pollution on emergency room admissions for COPD in our country. Relation with cardiovascular and total non-ac- cidental mortality at current levels of exposure has already become apparent with recent time-series studies provided in Niš $(11,12)$.

In this study, we evaluated the short-term association between black smoke (BS) and sulphur dioxide $\left(\mathrm{SO}_{2}\right)$, and all ages emergency room admissions for chronic obstructive pulmonary disease.

\section{MATERIAL AND METHODS}

Niš is the second biggest city in Serbia, a continental urban city area that covers $32 \mathrm{~km}^{2}$ with 171,000 inhabitants. A major source of air pollutants is fuel combustion including motor vehicle emissions and residential wood, coal, and oil burning. Air pollution in Nis is generally below the limit, and usually within the values recommended by the World Health Organization (WHO). The climate is moderate continental.

The daily number of emergency room admissions for COPD in 2002 was obtained from a register of hospital respiratory emergencies, which included, in practise, all COPD emergency room admissions in the area. For COPD visits we used International Classification of Diseases Revision 10 (ICD-10) code J44. Clinical records of all the emergency room visits were reviewed by trained physicians.

Air pollution data were provided by the Public Health Institute of Niš. Daily concentrations of BS and $\mathrm{SO}_{2}$ were obtained from the city monitoring network. Data included 24 hour average BS and $\mathrm{SO}_{2}$ levels. In view of the low ambient concentrations, monitoring of nitrogen dioxide $\left(\mathrm{NO}_{2}\right)$ and ozone $\left(\mathrm{O}_{3}\right)$ in Niš has been confined 
to only one station in recent years. We have therefore excluded both $\mathrm{NO}_{2}$ and $\mathrm{O}_{3}$ from our study. The height of the measurement points was $2 \mathrm{~m}$. The sampling protocol and the laboratory experiments was carried out by well trained and competent personnel and were done according to the Regulation of Guideline Values of Imission (Official Register Republic of Serbia 54/1992), as well as the International Organization for Standardization (ISO) standards and procedures. Pollutant measurements that failed to meet quality assurance criteria were excluded from the study. Missing air pollution data for $6 \%$ days of the period were treated as being missing completely at random and were dropped from the analyses.

Daily concentrations of BS $\left(\mu \mathrm{g} / \mathrm{m}^{3}\right)$ were measured by the refractometry method. The sampling was performed by the means of a pump operating with a flow rate of $1 \mathrm{l} / \mathrm{min}$ through Whattman No.1 paper filters. The concentration of sulphur dioxide $\left(\mu \mathrm{g} / \mathrm{m}^{3}\right)$ was measured by the pararosaniline method. The lower limit of detection of sulphur dioxide was $1.0 \mu \mathrm{g} / \mathrm{m}^{3}$.

The association between COPD emergency room admissions and weather variables was assessed in the models including the significant time-related variables. The weather variables studied were temperature (daily minimum, maximum, and mean), relative humidity, dew point temperature, air pressure, precipitation, rainfall, snowfall, overcast, and wind velocity. The weather variables were obtained from Republic Meteorological Department.

Generalized linear model (GLM) extending Poisson regression was applied allowing for overdispersion. This model used COPD emergency room admissions counts as the response variable, the natural cubic splines of the calendar time, weather variables, the day of the weak and season as indicator variables, and air pollution as predictor variable.

The model fitting was based on Akaike Information Criteria (AIC). To construct the model, the appropriate lag periods for weather variables and pollutants that gave the smallest AIC value were used. The degrees of freedom for natural spline functions of time and weather variables influence approximation that gave the smallest AIC value were selected. The pollutant was fitted as linear term. Analyses were done using S-PLUS 2000 software.

We assessed the effects of lagging exposure for $0,1,2$, and 3 days (lag 0 , $\operatorname{lag} 1, \operatorname{lag} 2$, and lag 3 days, respectively) as well as cumulative lags (lag 0-1, lag 0-2, lag 0-3). Lag 0 was defined as the 24-hour period from midnight to midnight, of the day of the admission, and lag 1 as the preceding 24-hour period, and so on. In cumulative lags (lag $0-1$, lag $0-2$, lag $0-3$ ), we examined average concentrations on the day of the admission and the previous days. Untransformed single pollutant concentrations were examined in unipollutant models. To study the combined effects of the pollutants, bipollutant models were constructed. Bipollutant models (in which both BS and sulphur dioxide were included together) examined the independence of any associations observed in unupollutant models.

The specific model formulation for emergency room admissions for COPD is given below:

$\mathrm{E}[\log (\mathrm{Y} i)]=\mathrm{a}+$ air pollution $+\operatorname{pol}\left(\right.$ minimum temperature ${ }_{\operatorname{lag}=1}$, degree $=2)+\operatorname{ncs}\left(\right.$ rainfall $\left._{\operatorname{lag}=3}, \mathrm{df}=3\right)+$ snowfall $+\operatorname{ncs}($ wind, $\mathrm{df}=7$ ) $+\operatorname{ncs}(i, \mathrm{df}=7)+$ day of week

where $i$ indicates the day in the time series, $Y i$ is the number of emergency room admissions on day $i, a$ is intercept, pol is polinomial function, $n c s$ is natural cubic spline and $d f$ is degree of freedom.

\section{RESULTS}

The descriptive data of daily emergency room admissions for COPD, pollutants concentrations, and weather variables are presented in Table 1. In the study, there were a total of 4,572 emergency room admissions for COPD in the city of Niš. The daily mean number of COPD emergency room admissions was $12.53 \pm 3.26$ (5 to 21 ). The daily mean level for BS was $21.25 \pm 21.12 \mu \mathrm{g} / \mathrm{m}^{3}$, minimum $2.00 \mu \mathrm{g} / \mathrm{m}^{3}$ and maximum 180.00 $\mu \mathrm{g} / \mathrm{m}^{3}$. The daily mean level for $\mathrm{SO}_{2}$ was $15.64 \pm 10.79 \mu \mathrm{g} / \mathrm{m}^{3}$, minimum $1.00 \mu \mathrm{g} / \mathrm{m}^{3}$ and maximum $58.00 \mu \mathrm{g} / \mathrm{m}^{3}$.

Table 1. Distribution of daily emergency room admissions for COPD, air pollutants and weather variables in Niš

\begin{tabular}{|l|c|c|c|c|c|c|c|}
\hline & Mean & SD & Min & 10th perc & Median & 90th perc & Max \\
\hline COPD admissions $(\mathrm{n})$ & 12.53 & 3.26 & 5.00 & 9.00 & 12.00 & 17.00 & 21.00 \\
\hline Black smoke $\left(\mu \mathrm{g} / \mathrm{m}^{3}\right)$ & 21.25 & 21.12 & 2.00 & 6.80 & 15.50 & 35.60 & 180.00 \\
\hline Sulphur dioxide $\left(\mu \mathrm{g} / \mathrm{m}^{3}\right)$ & 15.64 & 10.79 & 1.00 & 4.50 & 14.00 & 33.20 & 58.00 \\
\hline Mean temperature $\left({ }^{\circ} \mathrm{C}\right)$ & 12.64 & 8.43 & -10.80 & 0.56 & 12.80 & 23.20 & 29.90 \\
\hline Maximum temperature $\left({ }^{\circ} \mathrm{C}\right)$ & 18.66 & 9.79 & -8.20 & 3.20 & 20.00 & 30.00 & 37.00 \\
\hline Minimum temperature $\left({ }^{\circ} \mathrm{C}\right)$ & 7.60 & 7.54 & -12.60 & -2.54 & 7.80 & 17.00 & 23.50 \\
\hline Relative humidity $(\%)$ & 69.77 & 12.63 & 26.00 & 52.60 & 71.00 & 86.00 & 96.00 \\
\hline Dew point temperature $\left({ }^{\circ} \mathrm{C}\right)$ & 6.68 & 7.25 & -14.83 & -2.98 & 6.91 & 16.14 & 18.93 \\
\hline Air pressure $(\mathrm{mBar})$ & 993.65 & 6.18 & 979.00 & 986.10 & 993.10 & 1001.34 & 1014.00 \\
\hline Air pressure change $(\mathrm{mBar})$ & 2.86 & 1.76 & 0.20 & 1.00 & 2.50 & 5.14 & 10.30 \\
\hline Precipitation $(\mathrm{mm})$ & 1.81 & 4.21 & 0.00 & 0.00 & 0.00 & 6.24 & 25.90 \\
\hline Rainfall $(\mathrm{mm})$ & 1.66 & 4.15 & 0.00 & 0.00 & 0.00 & 6.08 & 26.00 \\
\hline Snowfall $(\mathrm{mm})$ & 0.15 & 0.97 & 0.00 & 0.00 & 0.00 & 0.00 & 12.70 \\
\hline Overcast $(\%)$ & 59.32 & 30.30 & 0.00 & 13.00 & 60.00 & 100.00 & 100.00 \\
\hline Wind velocity $(\mathrm{m} / \mathrm{s})$ & 1.76 & 1.27 & 0.00 & 0.28 & 1.58 & 3.70 & 7.61 \\
\hline
\end{tabular}


Table 2. ORs $(95 \% \mathrm{Cls}) / 10 \mu \mathrm{g} / \mathrm{m}^{3}$ increase in concentration of $B S$ for daily numbers of all age emergency room admissions for $C O P D$

\begin{tabular}{|c|c|c|c|c|c|c|c|c|}
\hline \multirow{2}{*}{ Model } & \multirow{2}{*}{ Lag } & \multirow{2}{*}{$\beta^{*}$} & \multirow{2}{*}{$\mathrm{SE}^{* *}$} & \multirow{2}{*}{$t$} & \multirow{2}{*}{$p$} & \multirow{2}{*}{ OR } & \multicolumn{2}{|c|}{$\mathrm{Cl}$} \\
\hline & & & & & & & Lower 95\% & Upper 95\% \\
\hline \multirow{7}{*}{ Unipollutant } & 0 & 0.00942 & 0.00836 & 1.13 & $p>0.05$ & 1.00946 & 0.99305 & 1.02615 \\
\hline & 1 & 0.01590 & 0.00808 & 1.97 & $p<0.05$ & 1.01603 & 1.00006 & 1.03226 \\
\hline & 2 & 0.01496 & 0.00792 & 1.89 & $p>0.05$ & 1.01508 & 0.99944 & 1.03096 \\
\hline & 3 & 0.00554 & 0.00785 & 0.71 & $p>0.05$ & 1.00555 & 0.99021 & 1.02114 \\
\hline & $0-1$ & 0.01740 & 0.00964 & 1.80 & $p>0.05$ & 1.01755 & 0.99850 & 1.03695 \\
\hline & $0-2$ & 0.02232 & 0.01047 & 2.13 & $p<0.05$ & 1.02257 & 1.00180 & 1.04378 \\
\hline & $0-3$ & 0.02156 & 0.01112 & 1.94 & $p>0.05$ & 1.02180 & 0.99977 & 1.04431 \\
\hline \multirow{7}{*}{ Bipollutant } & 0 & 0.01281 & 0.00916 & 1.40 & $p>0.05$ & 1.01289 & 0.99487 & 1.03123 \\
\hline & 1 & 0.01775 & 0.00901 & 1.97 & $p<0.05$ & 1.01790 & 1.00008 & 1.03604 \\
\hline & 2 & 0.01915 & 0.00881 & 2.17 & $p<0.05$ & 1.01934 & 1.00189 & 1.03708 \\
\hline & 3 & 0.01091 & 0.00876 & 1.25 & $p>0.05$ & 1.01097 & 0.99375 & 1.02849 \\
\hline & $0-1$ & 0.02064 & 0.01054 & 1.96 & $p<0.05$ & 1.02086 & 0.99998 & 1.04217 \\
\hline & $0-2$ & 0.02718 & 0.01151 & 2.36 & $p<0.05$ & 1.02755 & 1.00464 & 1.05099 \\
\hline & $0-3$ & 0.02836 & 0.01230 & 2.31 & $p<0.05$ & 1.02877 & 1.00427 & 1.05387 \\
\hline
\end{tabular}

*regression coefficient

${ }^{* *}$ standard error

Table 3. ORs $(95 \% \mathrm{Cls}) / 10 \mu \mathrm{g} / \mathrm{m}^{3}$ increase in concentration of $\mathrm{SO}_{2}$ for daily numbers of all age emergency room admissions for COPD

\begin{tabular}{|c|c|c|c|c|c|c|c|c|}
\hline \multirow{2}{*}{ Model } & \multirow{2}{*}{ Lag } & \multirow{2}{*}{$\beta^{*}$} & \multirow{2}{*}{$\mathrm{SE}^{* *}$} & \multirow{2}{*}{$t$} & \multirow{2}{*}{$p$} & \multirow{2}{*}{ OR } & \multicolumn{2}{|c|}{$\mathrm{Cl}$} \\
\hline & & & & & & & Lower 95\% & Upper $95 \%$ \\
\hline \multirow{7}{*}{ Unipollutant } & 0 & -0.00654 & 0.01704 & 0.38 & $p>0.05$ & 0.99348 & 0.96086 & 1.02722 \\
\hline & 1 & 0.00715 & 0.01700 & 0.42 & $p>0.05$ & 1.00717 & 0.97417 & 1.04129 \\
\hline & 2 & -0.00327 & 0.01680 & 0.19 & $p>0.05$ & 0.99673 & 0.96445 & 1.03010 \\
\hline & 3 & -0.01548 & 0.01677 & 0.92 & $p>0.05$ & 0.98464 & 0.95281 & 1.01753 \\
\hline & $0-1$ & 0.00041 & 0.01960 & 0.02 & $p>0.05$ & 1.00041 & 0.96270 & 1.03959 \\
\hline & $0-2$ & -0.00144 & 0.02134 & 0.07 & $p>0.05$ & 0.99856 & 0.95765 & 1.04122 \\
\hline & $0-3$ & -0.00818 & 0.02246 & 0.36 & $p>0.05$ & 0.99185 & 0.94914 & 1.03649 \\
\hline \multirow{7}{*}{ Bipollutant } & 0 & -0.01689 & 0.01861 & 0.91 & $p>0.05$ & 0.98325 & 0.94804 & 1.01977 \\
\hline & 1 & -0.00872 & 0.01886 & 0.46 & $p>0.05$ & 0.99131 & 0.95533 & 1.02865 \\
\hline & 2 & -0.02023 & 0.01859 & 1.09 & $p>0.05$ & 0.97997 & 0.94490 & 1.01634 \\
\hline & 3 & -0.02564 & 0.01869 & 1.37 & $p>0.05$ & 0.97469 & 0.93962 & 1.01106 \\
\hline & $0-1$ & -0.01626 & 0.02145 & 0.76 & $p>0.05$ & 0.98387 & 0.94336 & 1.02613 \\
\hline & $0-2$ & -0.02387 & 0.02348 & 1.02 & $p>0.05$ & 0.97641 & 0.93250 & 1.02240 \\
\hline & $0-3$ & -0.03217 & 0.02487 & 1.29 & $p>0.05$ & 0.96834 & 0.92227 & 1.01672 \\
\hline
\end{tabular}

${ }^{*}$ regression coefficient

${ }^{* *}$ standard error

After adjusting for weather and time-related variables, in unipollutant model, previous 1 day levels of BS were significantly associated with emergency room admissions for COPD (Table 2 and Fig. 1). For an increase of $10 \mu \mathrm{g} / \mathrm{m}^{3}$ of BS the daily number of admissions for COPD in previous 1 day increased 1.60\% $(\mathrm{OR}=1.01603$; 95\% CI: 1.00006 to 1.03226$)$. The magnitude of the associations for current and lagged (lag 2 and lag 3 ) levels of BS were lower and statistically not significant. The associations were slightly stronger with a cumulative measure of BS. The mean of the current and previous 2 days (lag $0-2)$ concentrations of black smoke led to an increase of $2.26 \%(\mathrm{OR}=1.02257 ; 95 \%$ CI: 1.00180 to 1.04378$)$ of COPD admissions. There was no significant association between emergency room admissions for COPD and levels of BS lagged $0-1$ and $0-3$.

After controlling for $\mathrm{SO}_{2}$, in bipollutant model, $\mathrm{BS}$ remained a strong indicator of COPD admissions for lag 1 levels $(\mathrm{OR}=1.01790 ; 95 \% \mathrm{CI}: 1.00008$ to 1.03604$)$. For an increase of $10 \mu \mathrm{g} / \mathrm{m}^{3}$ of BS, the daily number of admissions for COPD in 


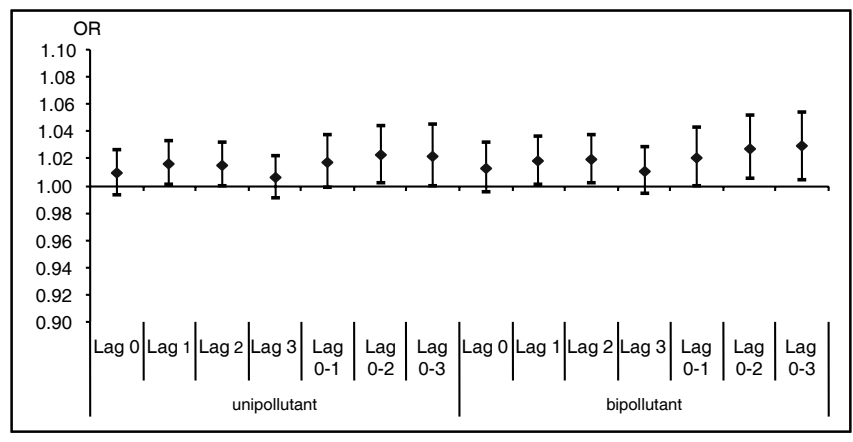

Fig. 1. Association between BS concentration and the number of all age emergency room admissions for COPD.

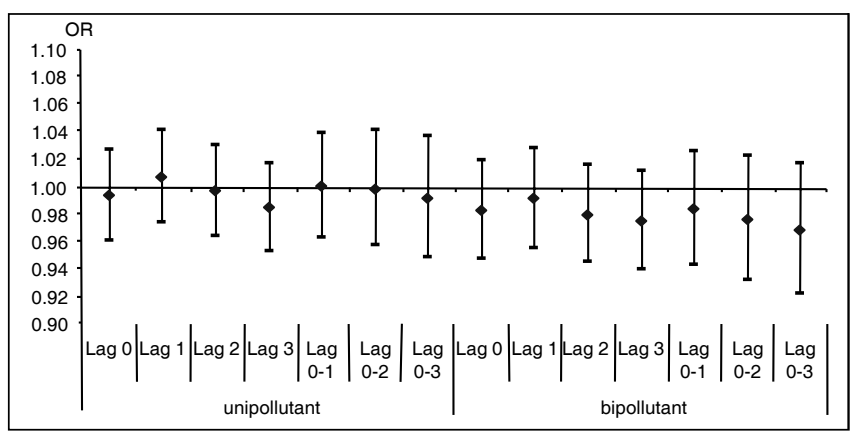

Fig. 2. Association between $\mathrm{SO}_{2}$ concentration and the number of all age emergency room admissions for COPD.

previous 2 days increased $1.93 \%(\mathrm{OR}=1.01934 ; 95 \% \mathrm{CI}: 1.00189$ to 1.03708 ). The mean of the current and previous 2 days (lag $0-2$ ) concentrations of BS led to a stronger associations with COPD emergency room admissions than in unipollutant model (2.75\% increase (OR $=1.02755 ; 95 \% \mathrm{CI}$ : 1.00464 to 1.05099$)$ for an increase of $10 \mu \mathrm{g} / \mathrm{m}^{3}$ of BS). For an increase of $10 \mu \mathrm{g} / \mathrm{m}^{3}$ of BS, increase in emergency room admissions for COPD (lag 0-1 and 0-3) was $2.09 \%(\mathrm{OR}=1.02086 ; 95 \% \mathrm{CI}: 0.99998$ to 1.04217$)$ and $2.88 \%$ $(\mathrm{OR}=1.02877 ; 95 \% \mathrm{CI}: 1.00427$ to 1.05387$)$, respectively.

Table 3 and Fig. 2 summarise the results of $\mathrm{SO}_{2}$ influence on emergency room admissions for COPD. No significant associations were found for $\mathrm{SO}_{2}$, even after controlling for black smoke.

\section{DISCUSSION}

Our study has shown a small but significant association of BS with emergency room admissions for COPD in Niš. In contrast, no significant associations were found for sulphur dioxide, even after controlling for black smoke.

Our results are consistent with previous studies showing associations of particulate pollutants with respiratory conditions. Time-series studies in North America have indicated that particles are related to emergency hospital admissions for respiratory conditions $(13,14)$. Additional investigations $(15,16)$, including studies in European cities (17-19), have suggested that air pollutants have a role in explaining variations in respiratory admissions.

Studies conducted in different cities in Europe, USA and Australia have consistently observed that admissions due to COPD increased on days with high pollution values (20-22). These results are consistent in demonstrating small but statistically significant increases in hospital emergency visits and admissions, in association with small elevations of air pollution (23).

In 1991, Sunyer et al. (24) reported time-series analyses of air pollution and emergency hospital admissions for COPD in Barcelona, Spain, during 1985-1986. They found a weak, but statistically significant association between admissions for obstructive pulmonary disease and $\mathrm{BS}, \mathrm{SO}_{2}$ and carbon monoxide (CO). Daily emergency room admissions for COPD increased by 0.02 and 0.01 for each $\mu \mathrm{g} / \mathrm{m}^{3}$ of $\mathrm{SO}_{2}$ and $\mathrm{BS}$, respectively.

The 5 year Barcelona study on emergency admissions for COPD confirmed previous results. In this study, an increase of $25 \mu \mathrm{g} / \mathrm{m}^{3}$ in $\mathrm{SO}_{2}$ was associated with a $6 \%$ to $9 \%$ increase in emergency room admissions for COPD during winter and summer, respectively. For BS, a similar change was found during winter, although the change was smaller in summer. The association of each pollutant with COPD admissions remained significant after control for the other pollutant (25).

Subsequent studies in the USA and Canada have focused on particles and $\mathrm{O}_{3}$ as the key pollutants associated with emergency room visits or hospital admissions for respiratory conditions and asthma $(26,27)$. However, European time-series analyses conducted within the Air Pollution on Health, European Approach (APHEA) initiative (28) have suggested that gaseous air pollutants are more important determinants of acute hospitalization for respiratory conditions than particulate mass.

The APHEA study reported significant associations between daily values of $\mathrm{SO}_{2}$ and the number of daily admissions for asthma in children (19), but not with asthma or COPD in adults $(17,19)$. In APHEA 2 project, in 8 European cities, it was found that an increase of $10 \mu \mathrm{g} / \mathrm{m}^{3}$ in $\mathrm{SO} 2$ was associated with a $0.6 \%(95 \%$ CI $0.0-1.2 \%$ ) increase in emergency room admissions for COPD and asthma at ages 65+years (29).

Burnett et al. (16) have underlined the importance of considering all available air pollution measures to assess the health effects of a single pollutant. Even though there are difficulties in separating the effects of particles from those of various gases, the gases themselves may be surrogates for fine and ultrafine particles.

Fine and ultrafine particles from combustion sources are the most likely causes of the respiratory effects, given the evidence from panel studies $(7,8)$. There is good evidence that particulate matter less than $10 \mu \mathrm{m}$ in diameter (PM10) has free radical activity and causes lung inflammation and epithelial injury (30). COPD patients have a systemic deficit in their antioxidant defenses (31), and particles could have produced a significant additive oxidative stress (32) as a response to the inflammation of the lungs $(33,34)$. Particles in the ultrafine size fraction have been shown to be able to penetrate into the alveolar region of the lung and in persons suffering from COPD and asthma the deposition is increased (35). In shortage of the equipment for measuring PM10 and particulate matter less than $2.5 \mu \mathrm{m}$ in diameter (PM2.5) we used black smoke measurement data. Black smoke represents a mixture with varying chemical and physical characteristics and different toxicity. However, WHO documents indicate that BS could serve as a useful marker in epidemiological studies and that BS concentration are much more directly influenced by local traffic sources than other pollutants (36).

People with COPD have been reported to be more susceptible to adverse health effects of air pollution than healthy people (6). However, the effects of ambient $\mathrm{BS}$ and $\mathrm{SO}_{2}$ on the symptoms of patients with COPD are not well known. While some positive associations between $\mathrm{BS}, \mathrm{SO}_{2}$, and respiratory disease, including $\mathrm{COPD}$, have 
been found, the results have not been consistent. Our analysis of unipollutant and bipollutant models suggests that emergency room admissions for COPD was primarily associated with BS.

Sulphur dioxide did not show a significant association with emergency room admissions for COPD in our study. Currently, the major source of pollution in Niš is fuel combustion and low quality motor vehicle emissions and $\mathrm{SO}_{2}$ might be a surrogate of the traffic pollution mixture. Sulphur dioxide, a highly soluble gas, was predomonantly stripped out of the upper airways (27), but the role of $\mathrm{SO}_{2}$ in exacerbating COPD was less coherent. Sulphur dioxide $\left(\mathrm{SO}_{2}\right)$ causes bronchoconstriction in normal and asthmatic subjects after short term exposures (within five minutes) in chamber studies (37). However, urban atmospheres in Europe rarely attain the levels of $\mathrm{SO}_{2}$ used in human experiments (200 ppb) (38).

Conclusions of our study indicates that air pollution is associated with increased emergency room admissions in Niš for COPD. These results are consistent with the international literature on the short-term health effects of air pollution, and provides evidence that current levels of air pollution in Niš are associated with adverse health outcomes. It appears that the health effects of BS mainly concern sensitive population subgroups with chronic respiratory illness, such as COPD. In contrast, no significant associations were found for $\mathrm{SO}_{2}$, even after controlling for black smoke. Our results indicate that $\mathrm{SO}_{2}$ may be acting as a surrogate for a specific mixture of other pollutants.

Frequent COPD exacerbations appear to be associated with worsening health outcomes, and to estimate the potential public health benefit of reducing air pollution below various thresholds is important. Even a weak effect of air pollution on health will constitute an important problem, because of ubiquity of exposure for large populations (39).

\section{REFERENCES}

1. Schwartz J. Air pollution and hospital admissions for respiratory disease. Epidemiology. 1996 Jan;7(1):20-8.

2. Schwartz J. Air pollution and hospital admissions for the elderly in Birmingham, Alabama. Am J Epidemiol. 1994 Mar 15;139(6):589-98.

3. Schwartz J. Air pollution and hospital admissions for the elderly in Detroit, Michigan. Am J Respir Crit Care Med. 1994 Sep;150(3):648-55.

4. Sunyer J, Schwartz J, Tobías A, Macfarlane D, Garcia J, Antó JM. Patients with chronic obstructive pulmonary disease are at increased risk of death associated with urban particle air pollution: a case - crossover analysis. Am J Epidemiol. 2000 Jan 1;151(1):50-6.

5. Brunekreef B, Dockery DW, Krzyzanowski M. Epidemiologic studies on short-term effects of low levels of major ambient air pollution components. Environ Health Perspect. 1995 Mar;103 Suppl 2:3-13.

6. Zanobetti A, Schwartz J, Gold D. Are there sensitive subgroups for the effects of airborne particles? Environ Health Perspect. 2000 Sep;108(9):841-5.

7. Peters A, Wichmann HE, Tuch T, Heinrich J, Heyder J. Respiratory effects are associated with the number of ultrafine particles. Am J Respir Crit Care Med. 1997 Apr;155(4):1376-83.

8. Dockery DW, Pope CA 3rd. Acute respiratory effects of particulate air pollution. Annu Rev Public Health. 1994 May;15:107-32.

9. Rom WN, Samet JM. Small particles with big effects. Am J Respir Crit Care Med. 2006 Feb 15;173(4):365-6.

10. World Health Organisation. Air quality guidelines for Europe. 2nd ed. WHO Regional Publications, European series no. 91. Copenhagen: WHO; 2000 .

11. Bogdanovic DC, Nikic DS, Milosevic ZG, Stankovic AM. Black smoke air pollution and daily non-accidental mortality in Nis, Serbia. Cent Eur J Med. 2006 Sep;1(3):292-7.

12. Stanković A, Nikić D, Nikolić M, Bogdanović D. Short-term effects of air pollution on cardiovascular mortality in elderly in Niš, Serbia. Cent
Eur J Public Health. 2007 Sep;15(3):95-8.

13. Schwartz J, Slater D, Larson TV, Pierson WE, Koenig JQ. Particulate air pollution and hospital emergency room visits for asthma in Seattle. Am Rev Respir Dis. 1993 Apr;147(4):826-31.

14. Bates DV, Sizto R. Air pollution and hospital admissions in Southern Ontario: the acid summer haze effect. Environ Res. 1987 Aug;43(2):31731 .

15. Moolgavkar SH, Luebeck EG, Anderson EL. Air pollution and hospital admissions for respiratory causes in Minneapolis-St. Paul and Birmingham. Epidemiology. 1997 Jul;8(4):364-70.

16. Burnett RT, Cakmak S, Brook JR, Krewski D. The role of particulate size and chemistry in the association between summertime ambient air pollution and hospitalization for cardiorespiratory diseases. Environ Health Perspect. 1997 Jun;105(6):614-20.

17. Anderson HR, Spix C, Medina S, Schouten JP, Castellsague J, Rossi G, et al. Air pollution and daily admissions for chronic obstructive pulmonary disease in 6 European cities: results from the APHEA project. Eur Respir J. 1997 May;10(5):1064-71.

18. Spix C, Anderson HR, Schwartz J, Vigotti MA, LeTertre A, Vonk JM, et al. Short-term effects of air pollution on hospital admissions of respiratory diseases in Europe: a quantitative summary of APHEA study results. Air Pollution and Health: a European Approach. Arch Environ Health. 1998 Jan-Feb;53(1):54-64.

19. Sunyer J, Spix C, Quénel P, Ponce-de-León A, Pönka A, Barumandzadeh $\mathrm{T}$, et al. Urban air pollution and emergency admissions for asthma in four European cities: the APHEA project. Thorax. 1997 Sep;52(9):760-5.

20. Sunyer J. Urban air pollution and chronic obstructive pulmonary disease: a review. Eur Resp J. 2001 May;17(5):1024-33.

21. Burnett RT, Dales R, Krewski D, Vincent R, Dann T, Brook JR. Associations between ambient particulate sulfate and admissions to Ontario hospitals for cardiac and respiratory diseases. Am J Epidemiol. 1995 Jul $1 ; 142(1): 15-22$.

22. Morgan G, Corbett S, Wlodarczyk J. Air pollution and hospital admissions in Sydney, Australia, 1990 to 1994. Am J Public Health. 1998 Dec;88(12):1761-6.

23. Katsouyanni K, Zmirou D, Spix C, Sunyer J, Schouten JP, Pönkä A, et al. Short-term effects of air pollution on health: a European approach using epidemiological time-series data. The APHEA project: background, objectives, design. Eur Respir J. 1995 Jun;8(6):1030-8.

24. Sunyer J, Anto JM, Murillo C, Saez M. Effects of urban air pollution on emergency room admissions for chronic obstructive pulmonary disease. Am J Epidemiol. 1991 Aug 1;134(3):277-86.

25. Sunyer J, Sáez M, Murillo C, Castellsague J, Martínez F, Antó JM. Air pollution and emergency room admissions for chronic obstructive pulmonary disease: a 5-year study. Am J Epidemiol. 1993 Apr 1;137(7):701-5.

26. Schwartz J. PM10, ozone, and hospital admissions for the elderly in Minneapolis-St. Paul, Minnesota. Arch Environ Health. 1994 SepOct;49(5):366-74.

27. Committee of the Environmental and Occupational Health Assembly of the American Thoracic Society. Health effects of outdoor air pollution. Am J Respir Crit Care Med. 1996 Jan;153(1):3-50.

28. Katsouyanni K, Schwartz J, Spix C, Touloumi G, Zmirou D, Zanobetti A, et al. Short term effects of air pollution on health: a European approach using epidemiologic time series data: the APHEA protocol. J Epidemiol Community Health. 1996 Apr;50 Suppl 1:S12-8.

29. Sunyer J, Atkinson R, Ballester F, Le Tertre A, Ayres JG, Forastiere F, et al; APHEA 2 study. Respiratory effects of sulphur dioxide: a hierarchical multicity analysis in the APHEA 2 study. Occup Environ Med. 2003 Aug;60(8):e2.

30. Li XY, Gilmour PS, Donaldson K, MacNee W. Free radical activity and pro-inflammatory effects of particulate air pollution (PM10) in vivo and in vitro. Thorax. $1996 \mathrm{Dec} ; 51(12): 1216-22$.

31. Rahman I, Morrison D, Donaldson K, MacNee W. Systemic oxidative stress in asthma, COPD, and smokers. Am J Respir Crit Care Med. 1996 Oct;154(4 Pt 1):1055-60.

32. Gilmour PS, Brown DM, Lindsay TG, Beswick PH, MacNee W, Donaldson K Adverse health effects of PM10 particles: involvement of iron in generation of hydroxyl radical. Occup Environ Med. 1996 Dec;53(12):817-22.

33. MacNee W.ABC of chronic obstructive pulmonary disease: pathology, pathogenesis, and pathophysiology. BMJ. 2006 May 20;332(7551):1202-4.

34. Salvi SS, Nordenhall C, Blomberg A, Rudell B, Pourazar J, Kelly FJ, et al. Acute exposure to diesel exhaust increases IL-8 and GRO- $\alpha$ production in healthy human airways. Am J Respir Crit Care Med. 2000 Feb;161(2 Pt 1):550-7.

35. Anderson PJ, WilsonJD, Hiller FC. Respiratory tract deposition of ultrafine particles in subjects with obstructive or restrictive lung disease. Chest. 1990 May;97(5):1115-20.

36. WHOWorking Group. Reporthealth aspects of air pollution with particulate matter, 
ozone and nitrogen dioxide. Bonn: WHO Regional Office for Europe; 2003.

37. Sheppard D, Wong WS, Uehara CF, Nadel JA, Boushey HA. Lower threshold and greater bronchomotor reponsiveness of asthmatic subjects to sulfur dioxide. Am Rev Respir Dis. 1980 Dec;122(6):873-8.

38. Linn WS, AvolEL, Peng RC, Shamoo DA, Hackney JD. Replicated dose-response study of sulfur dioxide effects in normal, atopic, and asthmatic volunteers. Am Rey
Respir Dis. 1987 Nov;136(5):1127-34

39. Katsouyanni K. Health effects of air pollution in southern Europe: are there interacting factors? Environ Health Perspect. 1995 Mar;103 Suppl 2:23-7.

Received July 7, 2008 Accepted in revised form October 31, 2008 